\title{
Sensitivity of Evapotranspiration Models to Onsite and Offsite Meteorological Data for a Ponderosa Pine Forest
}

\author{
Wonsook Ha, Abraham E. Springer, \\ Frances C. O'Donnell and Thomas E. Kolb \\ Additional information is available at the end of the chapter \\ http://dx.doi.org/10.5772/intechopen.68435
}

\begin{abstract}
Evapotranspiration (ET) is a major component of the water budget in most forests, in many cases exceeding $70 \%$ of annual precipitation. Due to limitations in time and resources, input data necessary to model ET are not always available for a study site, but offsite data from meteorological networks may be a suitable substitute. In this study, we evaluated three models for estimating ET, Priestly-Taylor (P-T), Shuttleworth-Wallace (S-W), and Penman-Monteith with dynamic stomatal resistance (P-M-d), in a ponderosa pine (Pinus ponderosa) forest in northern Arizona where eddy covariance data exist for comparison. We tested the sensitivity of the models to the use of offsite meteorological data from a weather station and offsite soil moisture data from two snow monitoring sites in the SNOTEL network. Onsite data are required for accurate ET estimation with the P-M-d model because of its complexity. Acceptable accuracy in ET estimation required onsite net radiation data for the P-T model and onsite vapor pressure deficit data for the S-W model; other input data can be obtained from nearby offsite weather stations. Errors in ET estimation produced by the use of offsite soil moisture data varied between two nearby SNOTEL sites. Recommendations about the use of offsite data are presented.
\end{abstract}

Keywords: air temperature, evapotranspiration, net radiation, ponderosa pine forest, vapor pressure deficit

\section{Introduction}

Evapotranspiration (ET) consists of evaporation from the soil surface and transpiration from the plant canopy [1]. It is one of the major components of the hydrologic cycle, accounting for up to $85 \%$ of annual precipitation in some forests $[2,3]$. Forest ET affects the frequency 
and timing of water saturation in soils [4]. Therefore, accurate estimation of ET is needed to predict stream flow emanating from forestland, to investigate hydrological processes, and to manage water resources [4, 5]. Forest ET is known to be hard to quantify [6]. It is a complex hydrological process $[7,8]$, which is influenced by interactions between the atmosphere, soil, and plant canopy $[9,10]$.

ET can be directly measured by lysimeters, water balance methods, and eddy covariance systems [6, 11-13]. Direct measurement of ET is difficult and requires large amounts of time, labor, and funding $[14,15]$. The eddy covariance method is considered the most reliable, but frequently is deficient from a lack of surface energy balance closure [16]. In the absence of direct measurements, ET can be modeled using climatic and ecosystem data [17-20]. Depending on the model used, estimating ET requires input data such as net radiation, air temperature, vapor pressure deficit, wind speed, and soil moisture. Net radiation is the difference between incoming and outgoing radiation [21], and a key variable for calculating potential ET. Air temperature, wind speed, and vapor pressure deficit control atmospheric conditions that impact ET [22]. Vapor pressure deficit also regulates stomatal resistance, which directly affects ET [23]. Soil moisture controls the availability of water for ET and is especially important in arid and semi-arid ecosystems, where ET is primarily water limited [24, 25]. The use of ET equations with fewer input variables is recommended when complete climatological data cannot be obtained [26]. Meteorological models that use onsite input data can produce estimates of ET similar to measurements by eddy covariance and are less expensive [27].

Installing equipment to measure onsite climatological and soil moisture data may still require more resources than are available to forest and water managers. Publicly available climatological data from weather stations may provide a reasonable substitute. Not all weather stations include the full set of measurements necessary to model ET. The U.S. Surface Climate Reference Network provides data from 114 stations in the USA that record all necessary meteorological data. Other networks, such as Ameriflux (ameriflux.ornl.gov), provide additional coverage. Soil moisture data needed to convert potential ET to actual ET are more limited, distributed across a range of government and academic networks, and summarized in the Texas A\&M University North American Soil Moisture Database (http://soilmoisture.tamu.edu/).

In the absence of a nearby weather station with a complete suite of measurements, certain inputs, such as net radiation and vapor pressure deficit, can be calculated using empirical models based on basic weather data [26, 28]. For example, Irmak et al. [28] developed equations to calculate net radiation from input variables such as minimum and maximum air temperatures, measured or predicted solar radiation, inverse relative distance from earth to sun, and mean relative humidity. Tabari et al. [26] derived regression equations to estimate potential ET from air temperature and solar radiation.

The impact on ET estimation of using offsite meteorological data rather than onsite data is unknown for most forest regions. In this study, we estimated ET for a ponderosa pine (Pinus ponderosa) forest from three meteorological models (Priestly-Taylor (P-T), ShuttleworthWallace (S-W), and Penman-Monteith with dynamic stomatal resistance (P-M-d)) using onsite and offsite data for net radiation, air temperature, vapor pressure deficit, wind speed, and soil moisture content ( $\theta$ or SMC in this chapter), and compared these estimates to measurements 
of ET at the same site using the eddy covariance approach as a standard [3,27]. The objectives of this study are to (1) compare the sensitivity of the P-T, S-W, and P-M-d meteorological ET models to the use of offsite meteorological data, (2) determine if the models can produce reliable results with offsite data, and (3) identify the input data that would result in the largest improvement in ET estimates if measured onsite. Results from the study are valuable to land and resource managers to better understand and predict the forest hydrological cycle using commonly available meteorological data and to prioritize the installation of monitoring equipment with limited resources.

\section{Material and methods}

\subsection{Study site}

The study site is a ponderosa pine forest located near Flagstaff, Arizona (Northern Arizona University Centennial Forest: $35^{\circ} 5^{\prime} 20.5^{\prime \prime} \mathrm{N}, 111^{\circ} 45^{\prime} 43.33^{\prime \prime} \mathrm{W}$, elevation $2180 \mathrm{~m}$ a.s.1.). Previously, this site was one of the three sites used to measure carbon and water fluxes in ponderosa pine forests of northern Arizona with the eddy covariance (EC) approach [3]. Thinning, harvesting, and fire did not occur at this site over the last century. The control site had an average leaf area index of $2.3 \mathrm{~m}^{2} \mathrm{~m}^{-2}$, basal area of $30 \mathrm{~m}^{2} \mathrm{ha}^{-1}$, and tree density of 853 trees ha- $[3,27,29]$. Location of study site is shown in Figure 1.

\subsection{ET model selection}

We selected the three best performing ET models from Ha et al. [27] based on the model performance statistics of root mean square error (RMSE) and coefficient of determination $\left(R^{2}\right)$ in comparisons with ET measured by the eddy covariance approach (Table 1). These three models were the Penman-Monteith dynamic (P-M-d), Priestley-Taylor (P-T), and ShuttleworthWallace (S-W) models. The P-M-d model updates the Penman-Monteith ET model by modeling canopy resistance as a function of environmental variables [30]. The P-T model is a simplification of the Penman-Monteith model that only requires inputs of net radiation, air temperature, and the Priestly-Taylor coefficient [31]. The S-W model was developed to estimate ET in sparse canopies and calculates soil evaporation and plant canopy transpiration separately [32]. Each of these models calculates potential ET, which we adjusted to actual ET using a relationship with soil moisture [27, 33]. ET calculations were made at the monthly scale because monthly data were available from weather stations and generally provided more accurate ET estimates for the study site than daily data when compared with ET measured with eddy covariance [27]. Detailed explanation of each model and its use in simulating ET at our study site can be found in Ref. [27].

\subsection{Offsite weather station data}

Daily offsite meteorological data were obtained from the Western Regional Climate Center (WRCC) available at http://www.wrcc.dri.edu/. Weather data were collected from a weather 


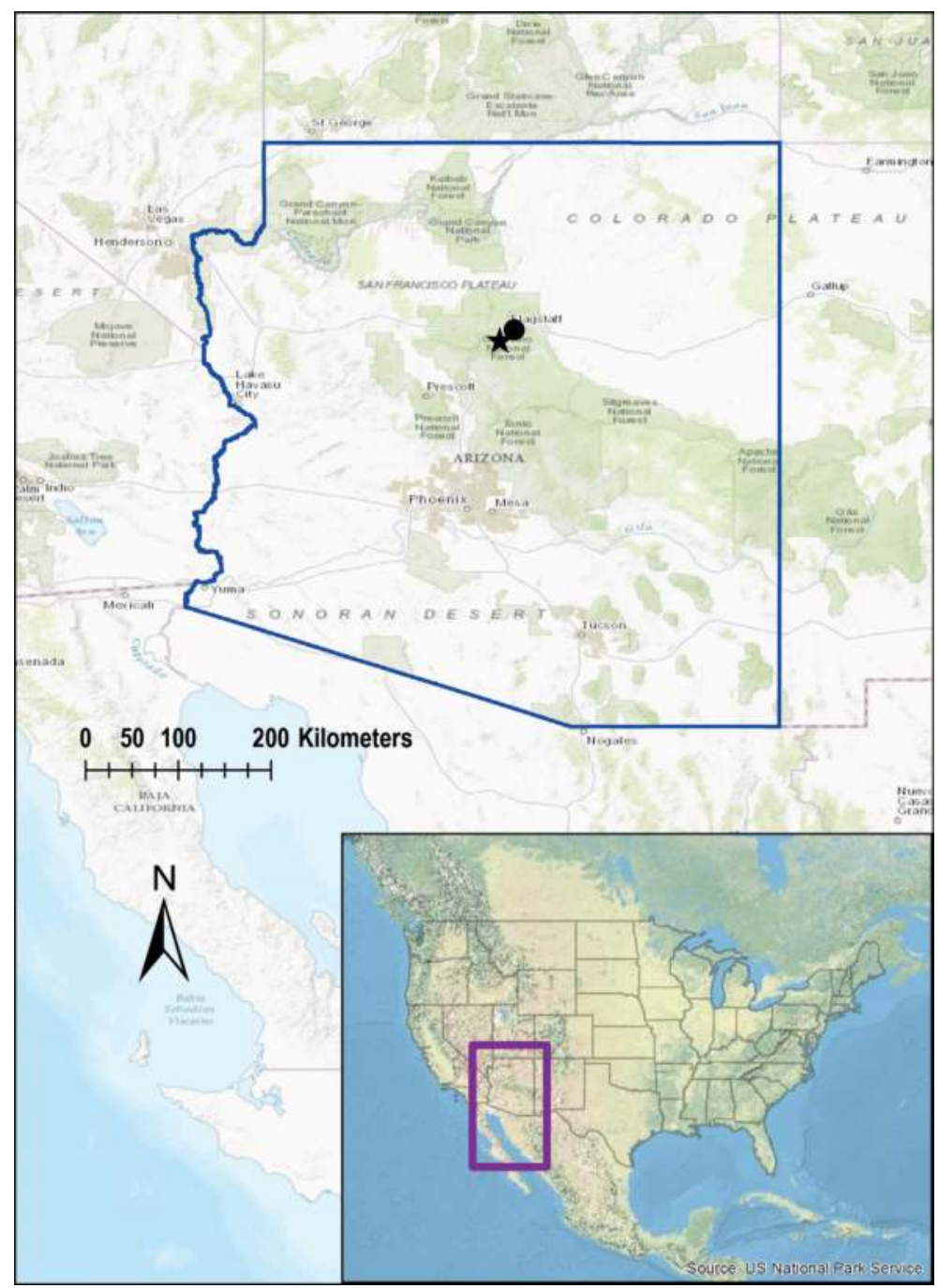

Figure 1. A ponderosa pine forest study site (a star) near the city of Flagstaff (a circle) in northern Arizona with an inset of coterminous United States of America (Basemap sources: www.esri.com, US National Park Service).

station near the Flagstaff Pulliam Airport (Flagstaff 4 SW, AZ; site number: 023009; latitude: $35^{\circ} 8^{\prime} \mathrm{N}$, longitude: $111^{\circ} 40^{\prime} \mathrm{W}$, ground elevation: $2135 \mathrm{~m}$; distance to the study site: $12.2 \mathrm{~km}$ ). Because net radiation $(\mathrm{Rn})$ data were not available from this station, they were calculated using an empirical equation from the FAO's Irrigation and Drainage paper 56 compiled by Ref. [34]. Inputs were daily offsite maximum and minimum absolute air temperature, actual vapor pressure, dew point temperature, relative humidity, station elevation, solar declination, 


\begin{tabular}{|c|c|c|c|c|c|c|}
\hline \multirow{2}{*}{$\frac{\text { C site }}{\text { Data }}$} & \multicolumn{3}{|c|}{ RMSE (mm month ${ }^{-1}$ ) } & \multicolumn{3}{|l|}{$R^{2}$} \\
\hline & P-M-d & P-T & S-W & P-M-d & $\mathrm{P}-\mathrm{T}$ & S-W \\
\hline $\begin{array}{l}\text { EC site data } \\
\text { only }\end{array}$ & 18.50 & 13.19 & 15.49 & 0.81 & 0.84 & 0.67 \\
\hline $\begin{array}{l}\text { Weather } \\
\text { station data } \\
(\mathrm{Rn}, \mathrm{ta}, \mathrm{vpd}, \\
\text { and u) and site } \\
\text { data (SWC, G, } \\
\alpha, \text { LAI, etc.) }\end{array}$ & 20.12 & 20.41 & 21.70 & 0.80 & 0.82 & 0.67 \\
\hline Station Rn & 18.68 & 20.23 & 15.31 & 0.81 & 0.82 & 0.67 \\
\hline Station ta & 19.21 & 13.30 & 15.47 & 0.83 & 0.84 & 0.67 \\
\hline Station vpd & 20.15 & 13.19 & 22.03 & 0.79 & 0.84 & 0.67 \\
\hline Station u & 19.11 & 13.19 & 15.49 & 0.81 & 0.84 & 0.67 \\
\hline $\begin{array}{l}\text { Weather } \\
\text { station data } \\
\text { and SNOTEL } \\
\text { happy jack } \\
\text { SMC data } \\
\text { (alpha } \\
\text { updated) }\end{array}$ & 42.04 & 20.08 & 30.17 & 0.26 & 0.49 & 0.62 \\
\hline $\begin{array}{l}\text { Weather } \\
\text { station data } \\
\text { and SNOTEL } \\
\text { Mormon } \\
\text { mtn summit } \\
\text { SMC (alpha } \\
\text { updated) }\end{array}$ & 23.11 & 51.90 & 21.91 & 0.70 & 0.50 & 0.62 \\
\hline
\end{tabular}

Table 1. Comparisons of root mean square error (RMSE) and coefficient of determination $\left(R^{2}\right)$ among three ET models. Numbers in bold indicate the best model for each dataset.

sunset hour angle, inverse relative distance from Earth to sun, sunset hour angle, latitude, and day of the year. Vapor pressure deficit $(\mathrm{kPa})$ was calculated using dew point temperature and relative humidity (\%) measured at the station.

Soil moisture data were obtained from the SNOTEL data collection network operated by the Natural Resources Conservation Service (NRCS) of the U.S. Department of Agriculture. Snowpack and climatic data (air and soil temperature and precipitation for all locations and soil moisture data for selected locations) are collected at sites across the Western U.S. Two SNOTEL sites were used, Happy Jack (site number: 969 ; latitude: $34^{\circ} 45^{\prime} \mathrm{N}$, longitude: $111^{\circ} 25^{\prime}$ W, elevation: $2326 \mathrm{~m}$; distance to study site: $60 \mathrm{~km}$ ) and Mormon Mountain Summit (site number: 1125 ; latitude: $34^{\circ} 58^{\prime} \mathrm{N}$, longitude: $111^{\circ} 31^{\prime} \mathrm{W}$, elevation: $2591 \mathrm{~m}$; distance to study site: $32 \mathrm{~km}$ ). These SNOTEL sites were selected because they were the closest to our study site and they had data available for our period of study (2007-2010). The Mormon Mountain Summit data are available only from June 2008. 


\subsection{Analysis of error propagation}

The error introduced in meteorological models of ET by using offsite station data likely can be reduced if some variables are measured onsite. To aid managers in prioritizing the installation of monitoring equipment with limited resources, an analysis was performed to determine how error in different input data combines to overall model error.

Each model was run at the monthly scale over 4 years (2007-2010) with all onsite input data to establish a baseline result. Then, model runs were performed using offsite data for each input variable and onsite data for the remaining input variables. The percent difference between the single offsite input model and the baseline was calculated. This procedure was repeated with each of the major offsite input variables (net radiation: $\mathrm{Rn}$, air temperature: ta, wind speed: $\mathrm{u}$, vapor pressure deficit: vpd, and soil moisture) to evaluate the error introduced by the use of offsite data.

For each model, the three variables to which the model was most sensitive were selected. Error was introduced to each of the three selected variables in increments of $1 \%$ to a maximum of $15 \%$ for variables positively related to ET or percent decrease for variables negatively related to ET. Thus, compounding errors acted in the same direction providing a worst case scenario estimate of overall model error. The models were run over ranges of percent error for the variables to determine all combinations of percent error in the three variables that produced $15 \%$ model error when averaged overall 4 years of simulation. These results show how variation in the accuracy of input variables affects model results.

\section{Results}

\subsection{Sensitivity of annual ET to offsite data}

Figure 2 shows the sensitivity of annual ET predicted by each model to the use of all offsite input data. When compared to eddy ET measurements at the annual scale, the S-W model performed well, but was sensitive to the use of offsite vpd data. The P-M-d model consistently underestimated eddy ET regardless of data sources. The P-T model consistently overestimated ET, and was sensitive to the use of offsite Rn. The use of offsite soil moisture data generally led to underestimation of ET for all models, especially for data from the Happy Jack site. When compared to modeled ET using all onsite data inputs, the use of offsite data inputs only led to significantly increased error in certain cases. For example, accuracy of the S-W and P-T models was reduced by the use of offsite vpd and Rn data, respectively.

\subsection{Sensitivity of monthly ET to offsite data}

ET simulated by the P-T model was sensitive to the use of offsite weather data used to calculate Rn (Figure 3(a)). The difference in ET predicted by the P-T model using all offsite data except for Rn was greater than a 15\% threshold of acceptability, especially during summer (data not shown). In contrast, using offsite Rn data produced acceptable predictions of ET by the P-M-d and S-W models (Figure 3(a)). 

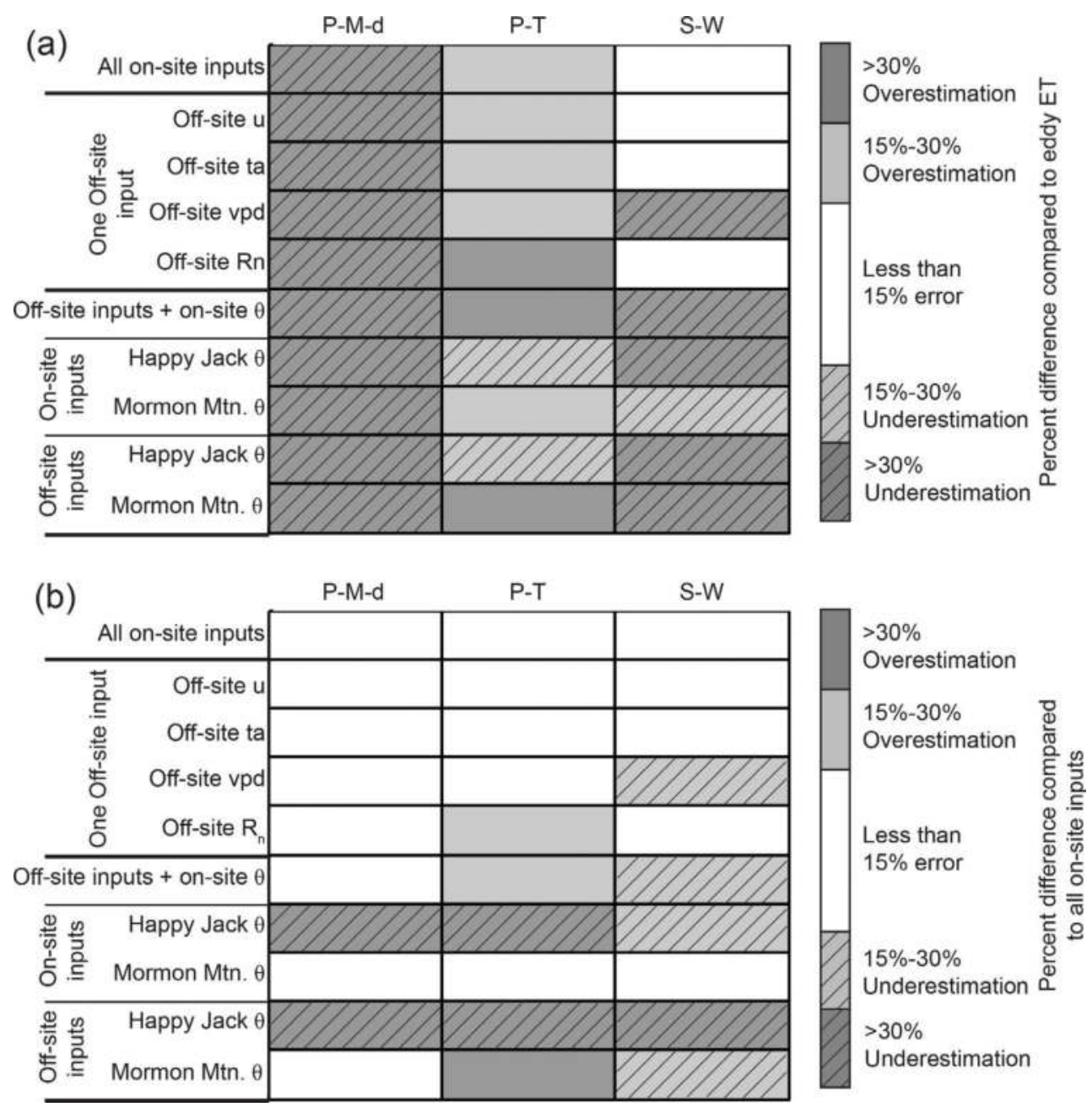

Figure 2. Effect of source of meteorological data for variables, wind speed (u), air temperature (ta), vapor pressure deficit (vpd), and net radiation ( $\mathrm{Rn})$, and soil moisture content $(\theta)$, on modeled ET as compared to (a) eddy covariance ET measurements and (b) modeled ET with all onsite inputs. Percent difference is calculated at the annual scale for three models, Penman-Monteith with dynamic canopy resistance (P-M-d), Priestly-Taylor (P-T), and Shuttleworth-Wallace (S-W), with all onsite meteorological inputs, a single offsite meteorological input, all offsite meteorological inputs, and offsite soil moisture from two SNOTEL sites, Happy Jack and Mormon Mountain Summit.

The P-M-d and P-T models were sensitive to the use of offsite ta data, whereas the S-W was not (Figure 3(b)). Inaccuracy in predicted ET from the P-M-d model was largest during winter when total ET is close to zero.

The P-M-d and S-W models were highly sensitive to the use of offsite vpd data, whereas the $\mathrm{P}-\mathrm{T}$ model was not because it does not use vpd as an input parameter (Figure 3(c)). Inaccuracy 


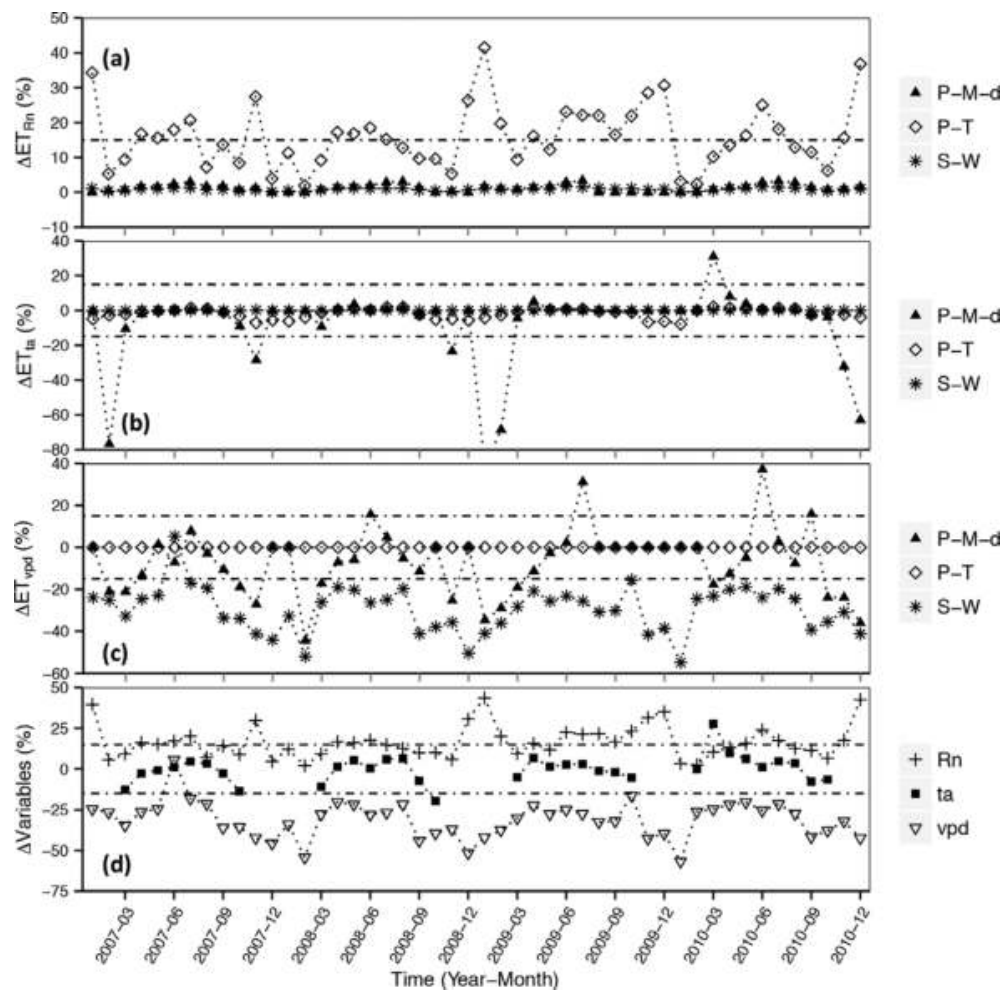

Figure 3. Percent difference in ET from models using all offsite input data and substitution of each input variable with onsite data (subscripted; Rn: net radiation, ta: air temperature, vpd: vapor pressure deficit) for the Penman-Monteith with dynamic canopy resistance (P-M-d), Priestly-Taylor (P-T), and Shuttleworth-Wallace (S-W) models (a-c); and percent difference in seasonal variation between offsite and SNOTEL sites Rn, ta, vpd (d). Dashed horizontal lines indicate $\pm 15 \%$ difference lines.

caused by the use of offsite vpd data was greater for the S-W model than the P-M-d model. Sensitivity to the use of offsite $\mathrm{u}$ was low for all models (data not shown).

Modeled Rn based on offsite weather data was consistently higher than based onsite Rn (Figure 3(d)), with the highest percent difference in summer. The percent difference between offsite and onsite vpd peaked during summer (Figure 3(d)). As opposed to Rn, offsite vpd was always lower than onsite vpd (Figure 3(d)). Offsite ta data generally provided a good substitute for onsite data, differing by less than $2.5^{\circ} \mathrm{C}$ throughout the study period. During winter, when temperatures were close to $0^{\circ} \mathrm{C}$, the percent difference between offsite and onsite temperatures could be quite large despite small absolute differences. Thus, these values are excluded from Figure 3(d).

The P-T and S-W models were most sensitive to the source of soil moisture content (SMC) data (Figure 4(a) and (c)). The P-T model was more sensitive than the S-W model, because SMC is 


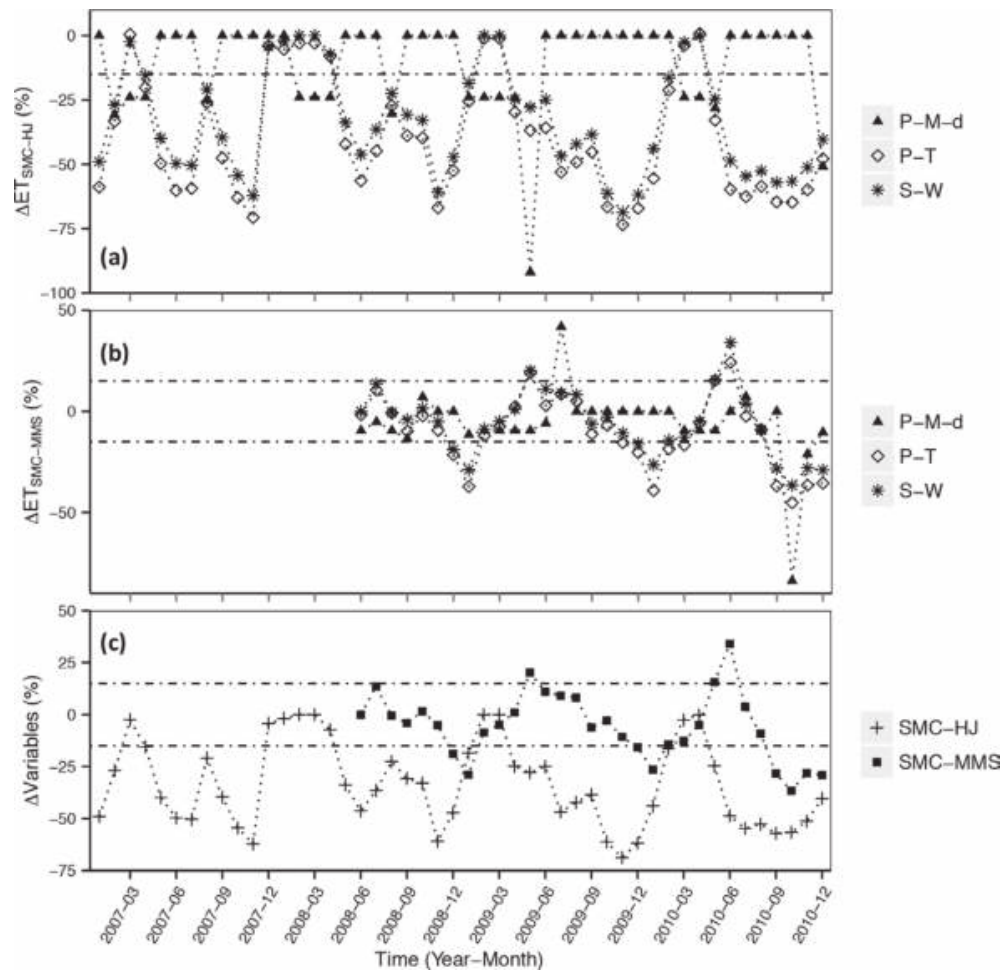

Figure 4. Percent difference in ET from models using all offsite input data and substitution of each input variable with onsite data (subscripted; SMC-HJ: soil moisture content from Happy Jack SNOTEL site, SMC-MMS: soil moisture content from Mormon Mountain Summit SNOTEL site) for the Penman-Monteith with dynamic canopy resistance (P-Md), Priestly-Taylor (P-T), and Shuttleworth-Wallace (S-W) models ( $\mathrm{a}$ and b); and percent difference in seasonal variations of soil moisture contents (SMC) between two SNOTEL sites (c). Dashed horizontal lines indicate $\pm 15 \%$ difference lines.

included in the calculation of the scaling coefficient $\alpha$ in the P-T model. The Happy Jack (HJ) SMC data produced a larger difference in $\triangle \mathrm{ET}$ than Mormon Mountain Summit (MMS) SMC data, which resulted from consistently lower SMC at the HJ site than onsite (Figure 4(c)). The SMC at the MMS site was higher than onsite SMC during summer, but lower during winter. SMC data from the MMS site were unavailable between January 2007 and May 2008, so no percent change was calculated during this time (Figure 4(b) and (c)).

The difference between ET modeled with offsite and onsite input data with the P-M-d model led to overprediction of ET during summer (Figure 5) due to the error introduced by vpd (Figure 3(c)), and underestimated ET during winter due both to error from vpd and ta (Figure 3(b)). The P-T model had a bigger difference than P-M-d between offsite and onsite modeled ET during summer due to error introduced by offsite Rn (Figure 3(a)). ET stimulated by the S-W model using offsite data was always lower than using onsite data except for June 2007 (Figure 5), a pattern driven by error introduced by offsite vpd. 


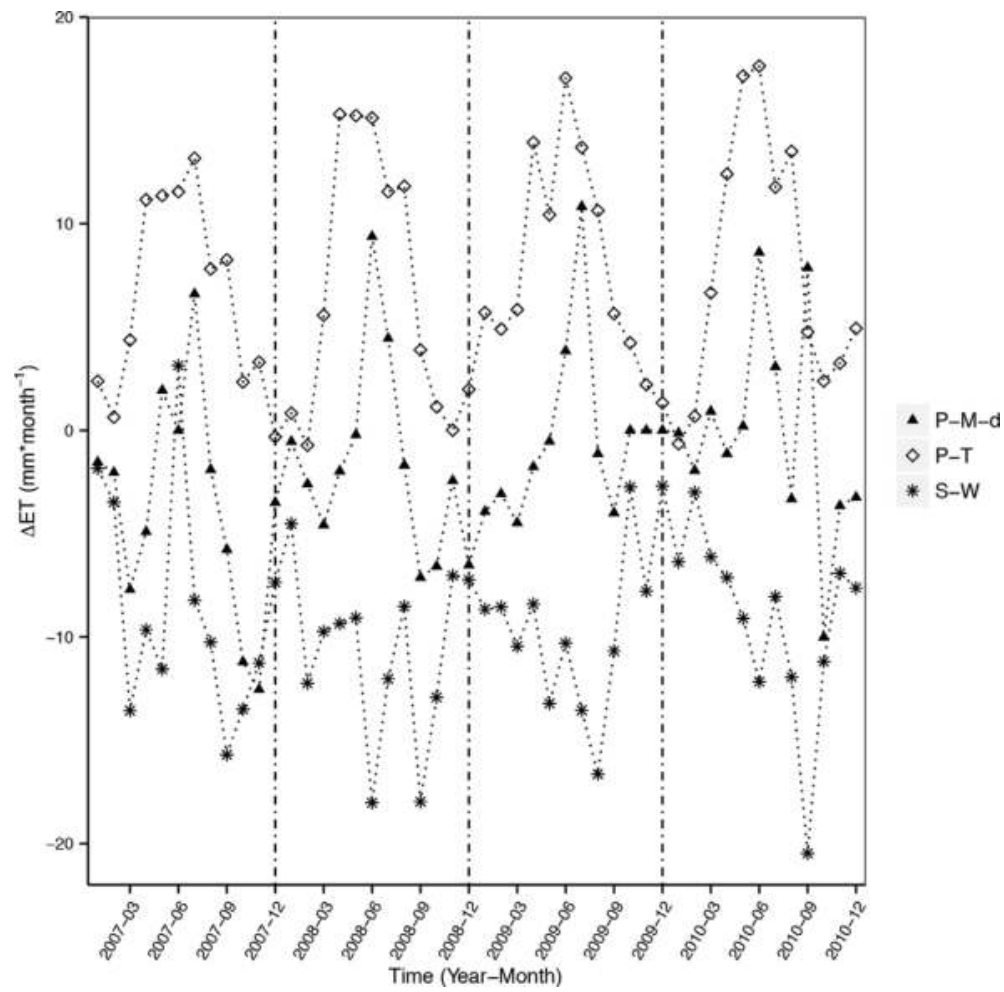

Figure 5. Difference in ET between modeled using offsite weather station input data and modeled with onsite data for the Penman-Monteith with dynamic canopy resistance (P-M-d), Priestly-Taylor (P-T), and Shuttleworth-Wallace (S-W) models.

\subsection{Sensitivity of annual ET to input errors}

Error in prediction of annual ET by the P-T model was most strongly influenced by error in Rn and, to a lesser extent, SMC (Figure 6(a)). Less than 15\% error in overall modeled ET was possible with large errors in ta $(>15 \%)$ and soil SMC $(>20 \%)$ if onsite Rn (i.e., $0 \%$ error in net radiation) is used. Error in the S-W model was most strongly influenced by error in vpd (Figure 6(b)). Large errors in soil moisture and temperature were acceptable if vpd is accurate. Because of the threshold responses and complex internal dynamics of the P-M-d model, we conclude that it is not a good choice for this type of error analysis. Therefore, we only considered the S-W and P-T models in this analysis.

\subsection{Relationships between onsite and offsite weather data}

A strong linear relationship occurred between onsite data and offsite weather- or SNOTELstation data with $R^{2} 0.72$ or higher for all variables, except for $u$ where the $R^{2}$ was 0.59 (Figure 7). 
(a)

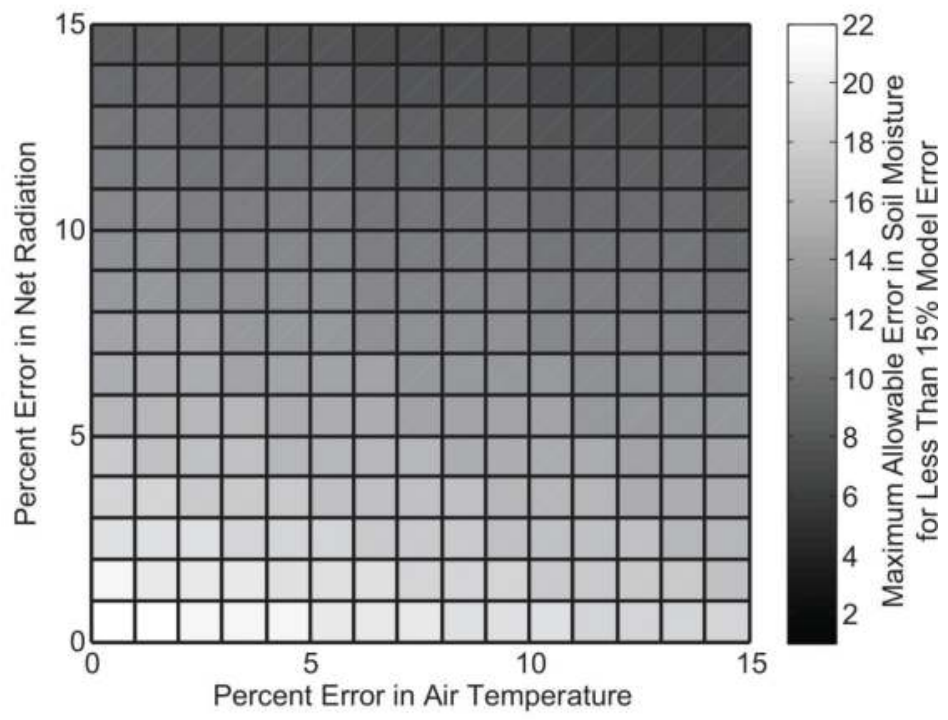

(b)

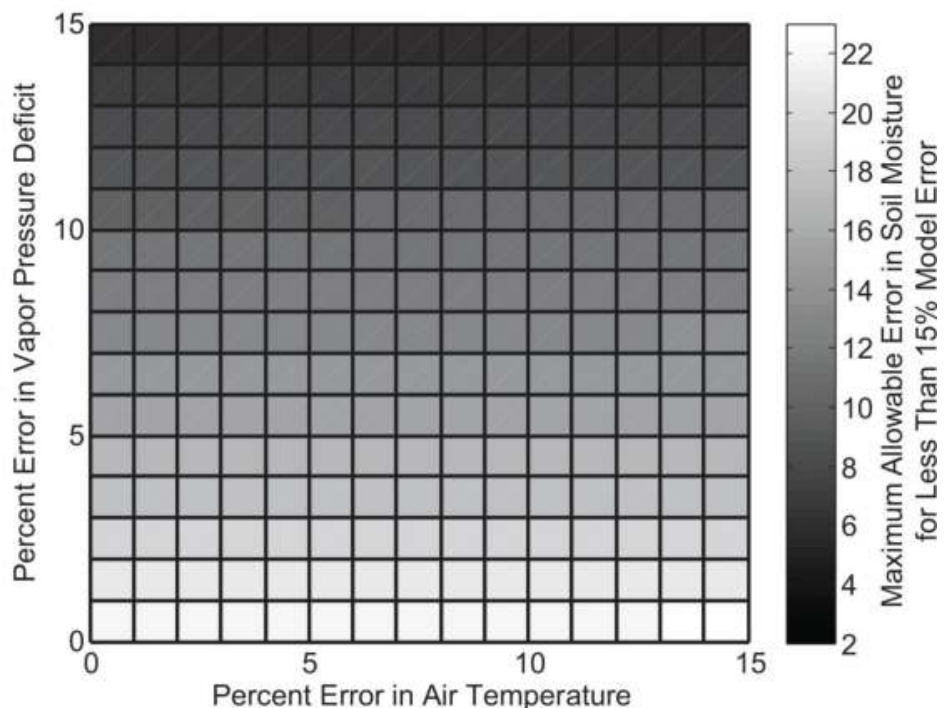

Figure 6. Combination of error in net radiation, air temperature, and soil moisture content that will produce $15 \%$ error in the Priestly-Taylor model (a), and vapor pressure deficit, air temperature, and soil moisture that will produce $15 \%$ error in the Shuttleworth-Wallace model (b). Model error is calculated at the annual scale over four years (2007-2010). Other model inputs were measured onsite. 


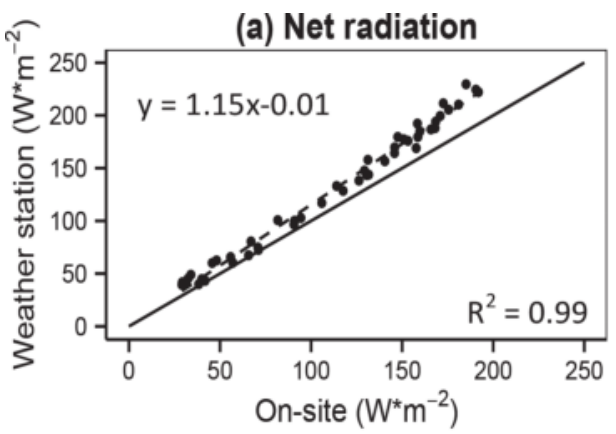

(b) Air temperature

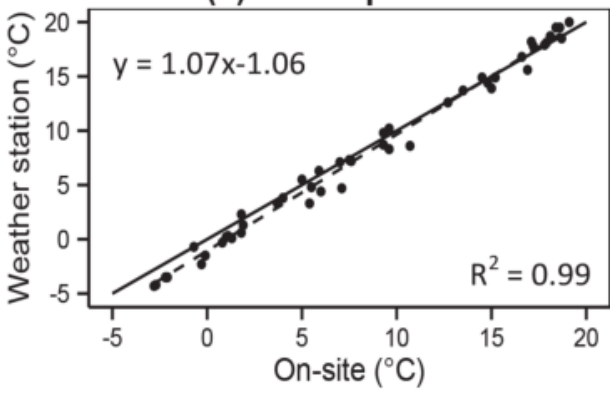

(c) Vapor pressure deficit

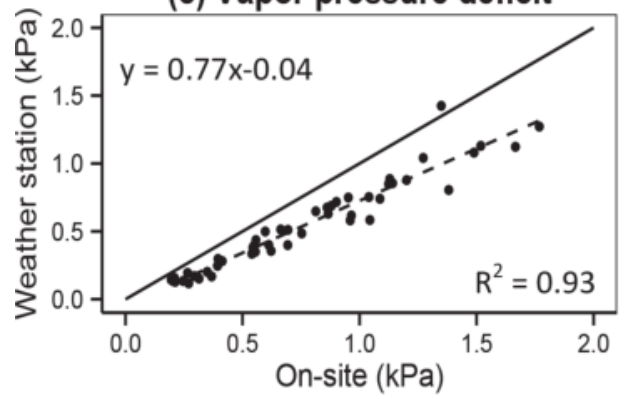

(d) Wind speed

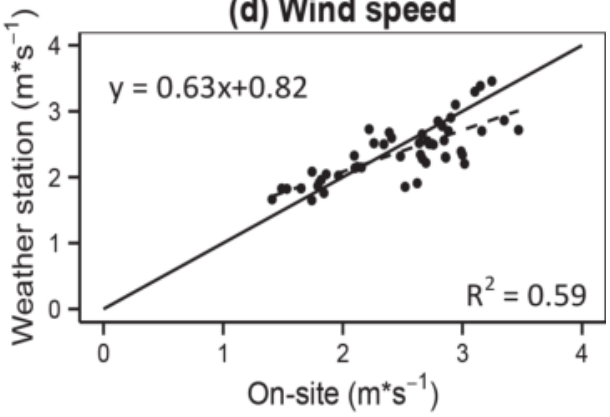

(e) Soil moisture content $(\mathrm{HJ})$

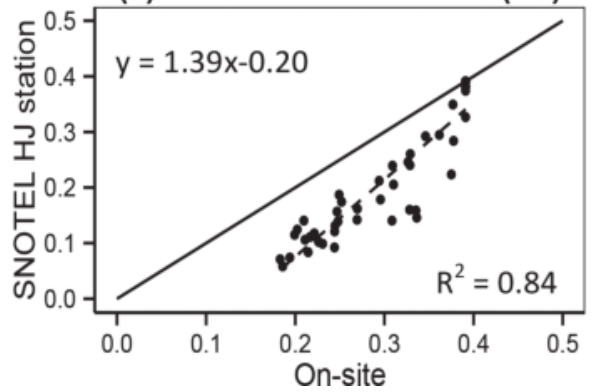

(f) Soil moisture content (MMS)

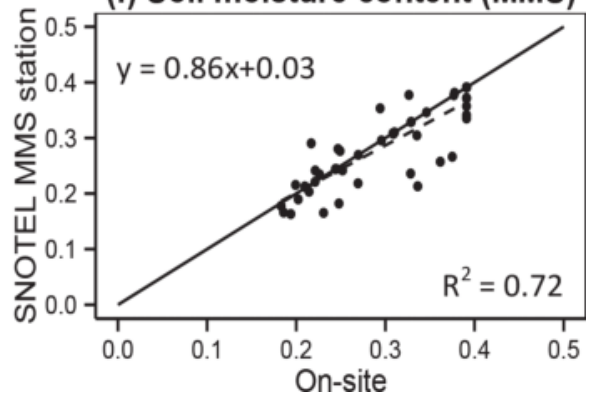

Figure 7. 1:1 relationship between onsite eddy tower versus offsite weather station input variables for (a) net radiation $\left(\mathrm{W} \mathrm{m}^{-2}\right),(\mathrm{b})$ air temperature $\left({ }^{\circ} \mathrm{C}\right)$, (c) vapor pressure deficit $(\mathrm{kPa})$, and $(\mathrm{d})$ wind speed $\left(\mathrm{m} \mathrm{s}^{-1}\right)$. Soil moisture content data from eddy tower versus Happy Jack (HJ) station (e) and Mormon Mountain Summit (MMS) (f) are also shown. The solid line indicates a 1:1 line and the dashed line is a regression line.

\section{Discussion}

The performance of three meteorological ET models (P-M-d, P-T, and S-W) in predicting ET measured by eddy covariance for the ponderosa pine forest in our study was affected by the 
source of input data. The P-M-d model performed well with offsite Rn data. In most cases, the P-T model performed well when offsite soil moisture content (SMC) data obtained from local SNOTEL sites replaced onsite SMC data. Likewise, the S-W model performed well when onsite $\mathrm{Rn}$, ta, and $\mathrm{u}$ data were replaced by offsite data from a nearby weather station. A previous study [27] reported that when using all onsite data, the ET predictions from the S-W model were the closest to ET measured by eddy covariance among five meteorological models, likely because our study site contains a mixture of surface layers (pine canopy, grass, bare soil), which the S-W model was designed to simulate [35-37].

Sensitivity to offsite meteorological data varied among models. The P-T model was sensitive to the use of offsite weather data used to predict Rn (Figure 2(a)). The P-M-d model was sensitive to the use of offsite ta and vpd data (Figure 2(b) and (c)). The S-W model was sensitive to the use of offsite vpd data (Figure 2(c)). From this result, we conclude that accurate measurement of vpd is important to properly estimate ET using S-W and P-M-d models. Models using Rn predicted from offsite weather data calculated consistently higher ET than models using onsite Rn data (Figure 2(d)), resulting in overestimation of ET by the P-T model, especially in summer (Figure 2(a)), when ET is highest and is the most important seasonal component to annual ET.

The suitability of offsite data as inputs into meteorological ET models depended on the variable and model. Offsite weather station data provided suitable estimates of onsite air temperature (Figure 2(d)) and therefore, air temperature was not a major source of error in all models for this study site. The sensitivity analysis (Figure 5) illustrates that errors in air temperature up to $15 \%$ are not likely to lead to large errors in ET estimates. Overestimation of winter ET occurs in the P-M-d model when onsite ta is used (Figure 2(b)), but winter ET is a small component of total annual ET. The dynamic model of stomatal conductance in the P-M-d model goes to zero when air temperature is below zero, and the overestimation by this model is the result of a threshold response when onsite air temperature is below zero and offsite air temperature is not. The vpd was consistently lower in the offsite data than the onsite data leading to overestimation of ET by the S-W model without a seasonal pattern. The effect of vpd on the $\mathrm{P}-\mathrm{M}-\mathrm{d}$ model is more complex because increases in vpd increase ET by increasing evaporative demand and decrease ET by reducing stomatal conductance. Thus, overestimation or underestimation of ET is possible when onsite vpd data are replaced with offsite data.

\section{Conclusions}

We investigated sensitivity to mixtures of on and offsite data inputs of three widely used models for calculating ET (P-M-d, P-T, and S-W) for a ponderosa pine forest where ET was measured previously by eddy covariance. The complexity of the P-M-d model makes it highly prone to inaccurate ET predictions with offsite data. The P-T and S-W models can provide reliable estimates of ET with selected input variables measured onsite and combined with offsite data for other inputs. Because measurement of some of these input data is expensive and difficult at specific field sites, resources should be devoted to onsite measurement of variables that model are most sensitive to. We found that offsite data from a nearby weather station were sufficient for air temperature and wind speed, whereas model accuracy in predicting ET 
was improved by onsite measurements of Rn for the P-T model, and vpd for the S-W model. The feasibility of using offsite soil moisture data depends on the proximity and similarity of the offsite monitoring location to the study site. Although, we did not determine the sensitivity of the models to data sources in forest conditions beyond one unmanaged ponderosa pine stand, our methods can be applied to other situations, where baseline measurements of ET by eddy covariance or other approaches exist.

\section{Acknowledgements}

Authors acknowledge the financial support from the WaterSMART Applied Science Grants for the Desert Landscape Conservation Cooperative of Bureau of Reclamation (Grant number: R12AC80912). Authors also thank anonymous reviewers for their proofs to improve this book chapter.

\section{Author details}

Wonsook Ha ${ }^{1 *}$, Abraham E. Springer ${ }^{2}$, Frances C. O'Donnell ${ }^{3}$ and Thomas E. Kolb ${ }^{4,5}$

*Address all correspondence to: wonsook-ha@uiowa.edu

1 Department of Civil and Environmental Engineering, University of Iowa, Iowa City, IA, United States

2 School of Earth Sciences and Environmental Sustainability, Northern Arizona University, Flagstaff, AZ, United States

3 Department of Civil Engineering, Auburn University, Auburn, AL, United States

4 School of Forestry, Northern Arizona University, Flagstaff, AZ, United States

5 Merriam-Powell Center for Environmental Research, Northern Arizona University, Flagstaff, AZ, United States

\section{References}

[1] Liang X, Lettenmaier DP, Wood EF, Burges SJ. A simple hydrologically based model of land surface water and energy fluxes for general circulation models. Journal of Geophysical Research: Atmospheres. 1994;99:14415-14428.

[2] Arain MA, Black TA, Barr AG, Griffis TJ, Morgenstern K, Nesic Z. Year-round observations of the energy and water vapour fluxes above a boreal black spruce forest. Hydrological Processes. 2003;17:3581-3600.

[3] Dore S, Montes-Helu M, Hart SC, Hungate BA, Koch GW, Moon JB, et al. Recovery of ponderosa pine ecosystem carbon and water fluxes from thinning and stand-replacing fire. Global Change Biology. 2012;18:3171-3185. 
[4] Vose JM, Sun G, Ford CR, Bredemeier M, Otsuki K, Wei X, et al. Forest ecohydrological research in the 21st century: What are the critical needs?. Ecohydrology. 2011;4:146-158.

[5] Ruhoff AL, Paz AR, Aragao LEOC, Mu Q, Malhi Y, Collischonn W, et al. Assessment of the modis global evapotranspiration algorithm using eddy covariance measurements and hydrological modelling in the Rio Grande basin. Hydrological Sciences Journal. 2013;58:1658-1676.

[6] Sun G, Alstad K, Chen J, Chen S, Ford CR, Lin G, et al. A general predictive model for estimating monthly ecosystem evapotranspiration. Ecohydrology. 2011;4:245-255.

[7] Kumar M, Raghuwanshi NS, Singh R, Wallender WW, Pruitt WO. Estimating evapotranspiration using artificial neural network. Journal of Irrigation and Drainage Engineering. 2002;128:224-233.

[8] Traore S, Wang Y-M, Kerh T. Artificial neural network for modeling reference evapotranspiration complex process in Sudano-Sahelian zone. Agricultural Water Management. 2010;97:707-714.

[9] Kondo J, Saigusa N, Sato T. A parameterization of evaporation from bare soil surfaces. Journal of Applied Meteorology. 1990;29:385-389.

[10] Reynolds JF, Kemp PR, Tenhunen JD. Effects of long-term rainfall variability on evapotranspiration and soil water distribution in the Chihuahuan desert: A modeling analysis. Plant Ecology. 2000;150:145-159.

[11] Rana G, Katerji N. Measurement and estimation of actual evapotranspiration in the field under mediterranean climate: A review. European Journal of Agronomy. 2000;13:125-153.

[12] Law BE, Falge E, Gu L, Baldocchi DD, Bakwin P, Berbigier P, et al. Environmental controls over carbon dioxide and water vapor exchange of terrestrial vegetation. Agricultural and Forest Meteorology. 2002;113:97-120.

[13] Vaughan PJ, Trout TJ, Ayars JE. A processing method for weighing lysimeter data and comparison to micrometeorological ETo predictions. Agricultural Water Management. 2007;88:141-146.

[14] Irmak S, Howell TA, Allen RG, Payero JO, Martin DL. Standardized ASCE PenmanMonteith: Impact of sum-of-hourly vs. 24-hour timestep computations at reference weather station sites. Transactions of the ASAE. 2005;48:1063-1077.

[15] Temesgen B, Eching S, Frame K. Comparing net radiation estimation methods: CIMIS versus Penman-Monteith. Journal of Irrigation and Drainage Engineering. 2007;133:265-271.

[16] Twine TE, Kustas WP, Norman JM, Cook DR, Houser PR, Meyers TP, et al. Correcting eddy-covariance flux underestimates over a grassland. Agricultural and Forest Meteorology. 2000;103:279-300.

[17] Monteith JL. Evaporation and the environment. Symposium of the Society of Exploratory Biology. 1965;19:205-234. 
[18] Wilson KB, Hanson PJ, Mulholland PJ, Baldocchi DD, Wullschleger SD. A comparison of methods for determining forest evapotranspiration and its components: Sap-flow, soil water budget, eddy covariance and catchment water balance. Agricultural and Forest Meteorology. 2001;106:153-168.

[19] Allen RG, Tasumi M, Trezza R. Satellite-based energy balance for mapping evapotranspiration with internalized calibration (metric)-model. Journal of Irrigation and Drainage Engineering. 2007;133:380-394.

[20] Baldocchi D. Measuring fluxes of trace gases and energy between ecosystems and the atmosphere-The state and future of the eddy covariance method. Global Change Biology. 2014;20:3600-3609.

[21] Su Z, Roebeling RA, Schulz J, Holleman I, Levizzani V, Timmermans WJ, et al. Observation of hydrological processes using remote sensing. In: Wilderer P, editor. Treatise on water science. Oxford, UK: Academic Press; 2011. pp. 351-399.

[22] Morillas L, Villagarcía L, Domingo F, Nieto H, Uclés O, García M. Environmental factors affecting the accuracy of surface fluxes from a two-source model in mediterranean drylands: Upscaling instantaneous to daytime estimates. Agricultural and Forest Meteorology. 2014;189-190:140-158.

[23] Dickinson RE, Henderson-Sellers A, Rosenzweig C, Sellers PJ. Evapotranspiration models with canopy resistance for use in climate models, a review. Agricultural and Forest Meteorology. 1991;54:373-388.

[24] Williams CA, Albertson JD. Contrasting short- and long-timescale effects of vegetation dynamics on water and carbon fluxes in water-limited ecosystems. Water Resources Research. 2005;41:W06005. DOI: doi:10.1029/2004WR003750

[25] Chen X, Rubin Y, Ma S, Baldocchi D. Observations and stochastic modeling of soil moisture control on evapotranspiration in a Californian Oak Savanna. Water Resources Research. 2008;44:W08409. DOI: doi:10.1029/2007WR006646

[26] Tabari H, Grismer M, Trajkovic S. Comparative analysis of 31 reference evapotranspiration methods under humid conditions. Irrigation Science. 2013;31:107-117.

[27] Ha W, Kolb TE, Springer AE, Dore S, O'Donnell FC, Martinez Morales R, et al. Evapotranspiration comparisons between eddy covariance measurements and meteorological and remote-sensing-based models in disturbed ponderosa pine forests. Ecohydrology. 2015;8:1335-1350.

[28] Irmak S, Irmak A, Jones JW, Howell TA, Jacobs JM, Allen RG, et al. Predicting daily net radiation using minimum climatological data. Journal of Irrigation and Drainage Engineering. 2003;129:256-269.

[29] Dore S, Kolb TE, Montes-Helu M, Sullivan BW, Winslow WD, Hart SC, et al. Long-term impact of a stand-replacing fire on ecosystem $\mathrm{CO}_{2}$ exchange of a ponderosa pine forest. Global Change Biology. 2008;14:1801-1820. 
[30] Stewart JB. Modeling surface conductance of pine forest. Agricultural and Forest Meteorology. 1988;43:19-35.

[31] Priestley CHB, Taylor RJ. On the assessment of surface heat flux and evaporation using large scale parameters. Monthly Weather Review. 1972;100:81-92.

[32] Shuttleworth WJ, Wallace JS. Evaporation from sparse crops-an energy combination theory. Quarterly Journal of the Royal Meteorological Society. 1985;111:839-855.

[33] Flint AL, Childs SW. Use of the Priestley-Taylor evaporation equation for soil water limited conditions in a small forest clearcut. Agricultural and Forest Meteorology. 1991;56:247-260.

[34] Allen RG, Pereira LS, Raes D, Smith M. Crop evapotranspiration (guidelines for computing crop water requirements). Rome, Italy: FAO; 1998. 333 p.

[35] Ortega-Farias S, Poblete-Echeverría C, Brisson N. Parameterization of a two-layer model for estimating vineyard evapotranspiration using meteorological measurements. Agricultural and Forest Meteorology. 2010;150:276-286.

[36] Lagos L, Martin D, Verma S, Irmak S, Irmak A, Eisenhauer D, et al. Surface energy balance model of transpiration from variable canopy cover and evaporation from residuecovered or bare soil systems: Model evaluation. Irrigation Science. 2013;31:135-150.

[37] Zhu G, Su Y, Li X, Zhang K, Li C. Estimating actual evapotranspiration from an alpine grassland on Qinghai-Tibetan plateau using a two-source model and parameter uncertainty analysis by Bayesian approach. Journal of Hydrology. 2013;476:42-51. 
